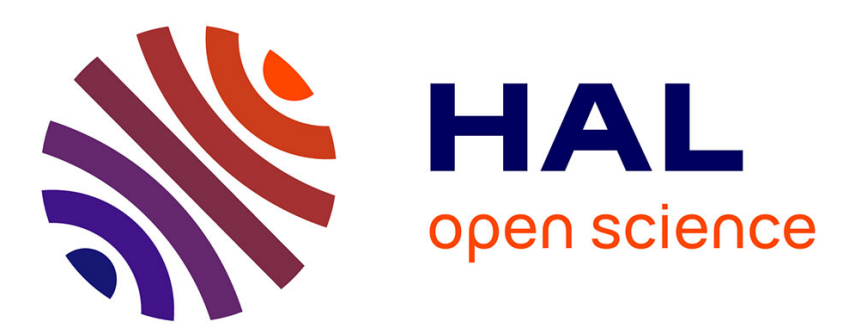

\title{
Ultrasonic impact damage assessment in 3D woven composite materials
}

E. Mannaî, B. Lamboul, J.M. Roche

\section{To cite this version:}

E. Mannaî, B. Lamboul, J.M. Roche. Ultrasonic impact damage assessment in 3D woven composite materials. 41st Annual Review of Progress in Quantitative Nondestructive Evaluation Conference (QNDE 2014), Jul 2014, BOISE, United States. hal-01132158

\section{HAL Id: hal-01132158 https://hal.science/hal-01132158}

Submitted on 16 Mar 2015

HAL is a multi-disciplinary open access archive for the deposit and dissemination of scientific research documents, whether they are published or not. The documents may come from teaching and research institutions in France or abroad, or from public or private research centers.
L'archive ouverte pluridisciplinaire HAL, est destinée au dépôt et à la diffusion de documents scientifiques de niveau recherche, publiés ou non, émanant des établissements d'enseignement et de recherche français ou étrangers, des laboratoires publics ou privés. 


\title{
T I R É

\section{Ultrasonic impact damage assessment in 3D woven composite materials}

\author{
E. Mannaî, B. Lamboul, J.M. Roche
}

41st Annual Review of Progress in Quantitative Nondestructive Evaluation Conference (QNDE 2014) BOISE, U.S.A 20-25 juillet 2014

\section{ONERA}

THE FRENCH AEROSPACE LAB 

Ultrasonic impact damage assessment in 3D woven composite materials

Evaluation non-destructive ultrasonore de l'endommagement d'impact dans des matériaux composites $3 D$

par

E. Mannaî, B. Lamboul, J.M. Roche

\section{Résumé traduit :}

Une approche non-destructive ultrasonore est proposée pour estimer l'endommagement créé dans un matériau composite tissé 3D par impact basse vitesse. Les données obtenues sont amenées à être utilisées pour valider les performances des pièces composites en terme de tolérance aux dommages et pour consolider la fiabilité des modèles de prévision de l'endommagement. Une procédure de seuillage, évolutive en profondeur, basée sur la réflectivité de trous à fond plat, est appliquée afin de discriminer les échos, signature de l'endommagement, du bruit structural, dans le cas d'une plaque composite tissée 3D de $3 \mathrm{~mm}$ d'épaisseur, impactée à différents niveaux d'énergie. Une représentation schématique 3D des échos détectés est en outre proposée, afin de faciliter l'observation de l'endommagement par l'utilisateur. Enfin, l'article analyse des données statistiques réalisées sur les échos détectés, afin de quantifier la résistance à l'impact de la plaque testée. 



\title{
Ultrasonic impact damage assessment in 3D woven composite materials
}

\author{
E. Mannai ${ }^{1}$, B. Lamboul ${ }^{1, \text { a) }}$ and J.M. Roche ${ }^{1}$ \\ ${ }^{1}$ Onera- 29, avenue de la Division Leclerc- 92320 Châtillon, France. \\ ${ }^{a)}$ Corresponding author: benjamin.lamboul@onera.fr
}

\begin{abstract}
An ultrasonic nondestructive methodology is proposed for the assessment of low velocity impact damage in a 3D woven composite material. The output data is intended for material scientists and numerical scientists to validate the damage tolerance performance of the manufactured materials and the reliability of damage modeling predictions. A depth-dependent threshold based on the reflectivity of flat bottom holes is applied to the ultrasonic data to remove the structural noise and isolate echoes of interest. The methodology was applied to a $3 \mathrm{~mm}$ thick 3D woven composite plate impacted with different energies. An artificial 3D representation of the detected echoes is proposed to enhance the spatial perception of the generated damage by the end user. The paper finally highlights some statistics made on the detected echoes to quantitatively assess the impact damage resistance of the tested specimens.
\end{abstract}

\section{INTRODUCTION}

3D woven composite materials are increasingly used in the aeronautical industry for their flexibility in the design of complex parts (e.g. fan blades), and their high tolerance to low-velocity impacts compared to standard composite laminates made of unidirectional plies [1,2]. A significant research effort is currently focused on the development of reliable models for the prevision of the mechanical resistance and the failure mechanisms of this type of material [35]. In this context, different experimental techniques were investigated for damage monitoring under tensile loading tests [6,7], and for the study of impact damage [8-11]. The impact-induced damage patterns observed in this type of material are very complex and consist of multiple, diffuse cracking and decohesions at different scales [8]. These damage patterns make most standard NDT techniques (infrared thermography and ultrasonic testing) not readily applicable or not fully effective. For ultrasonic inspections, two major difficulties may be pointed out. First, the fibre reinforcement of this type of material is very echogenic at the usual wavelengths used and generates what could be called a "structural noise". Second, the defects are small in size (much smaller than a delamination after impact in a standard laminate), and not necessarily favorably oriented for detection using normal incidence, because of fibre undulations associated with the textile nature of the reinforcement.

The goal of this paper is to propose a methodology for assessing the damage resistance performance of these materials and provide numerical and material scientists some quantitative experimental data to be compared with model previsions. The paper first illustrates the difficulties encountered with standard ultrasonic scanning with the tested material. In a second part, a depth-thresholding approach is presented to reliably detect ultrasonic amplitude echoes above the structural noise level, based on different Flat Bottom Holes (FBH) reflectivity at different depths. A 3D artificial reconstruction of the extracted damage information and volume rendering is presented to highlight the damage spatial distribution. Finally, the resistance of the material to low-velocity impacts is discussed in terms of statistics from the collected echoes positions and amplitudes. 


\section{CURRENT LIMITATIONS WITH STANDARD ULTRASONIC C-SCANS}

The studied 3D woven composite material consists of carbon-fibre yarns woven in 3D in an epoxy resin matrix. The out-of-plane reinforcement (Fig.1) provides better out-of-plane mechanical properties and low-velocity impact resistance compared to standard laminates. As can be expected, damage mechanisms in woven composites also differ from standard unidirectional laminates. The typical impact-induced damage consists of multiple cracks and decohesions, with different scales and orientations (see microscopic observations in Fig.2).

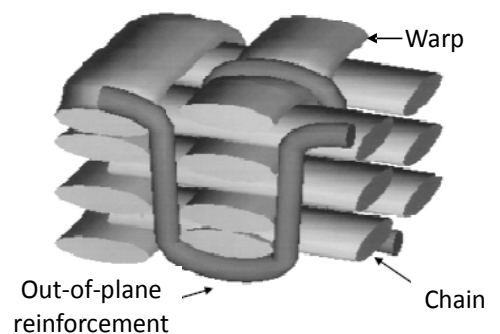

FIGURE 1. Schematic representation of the reinforcement architecture of a 3D woven composite material.
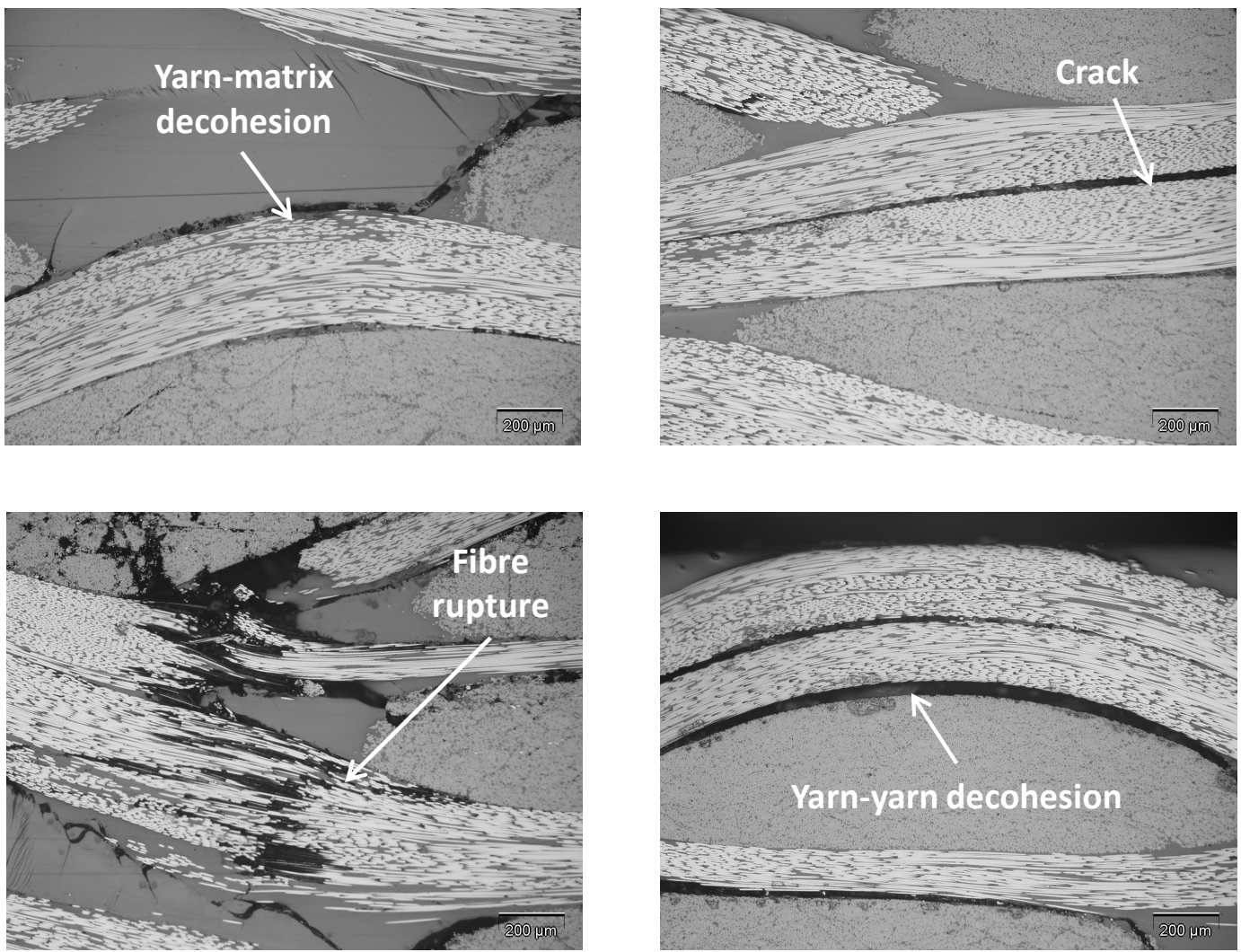

FIGURE 2. Microscopic observation of typical impact-induced damage in a 3D woven composite material obtained on the $3 \mathrm{~mm}$ plate specimen under investigation.

As stated in the introduction, the difficulties associated with the inspection of woven composites originate both from the typology of defects (small size, possible disorientation from beam normal due to the undulation of the fibre bundles) and the depth-dependent structural noise associated with echoes from the fibre bundles reinforcement. These materials may also exhibit a very high attenuation at conventional ultrasonic NDT frequencies. To illustrate 
these aspects, Fig3.a shows an immersion C-scan of a $12 \mathrm{~J}$ impact damage, with a gated range window centered around a depth of $2 \mathrm{~mm}$. A defect pattern is clearly visible in Fig3.a, but the surrounding structural noise pattern makes accurate defect discrimination and sizing quite difficult. Another source of difficulty also arises from the orientation of the decohesions, which are not always favorably imaged by standard C-scans representations. A 3D representation will be proposed in the final section of this paper as an alternative to conventional C-scan amplitude maps. Fig. 3b shows a C-scan with a gated range window centered on the bottom echo of the plate. As seen on this figure, damage shadows this echo and a global estimation of the damaged area is possible from the scan area with a loss in amplitude of the bottom echo. To date, this estimated damaged area has been the only quantitative ultrasonic information used at Onera in order to validate damage model predictions.

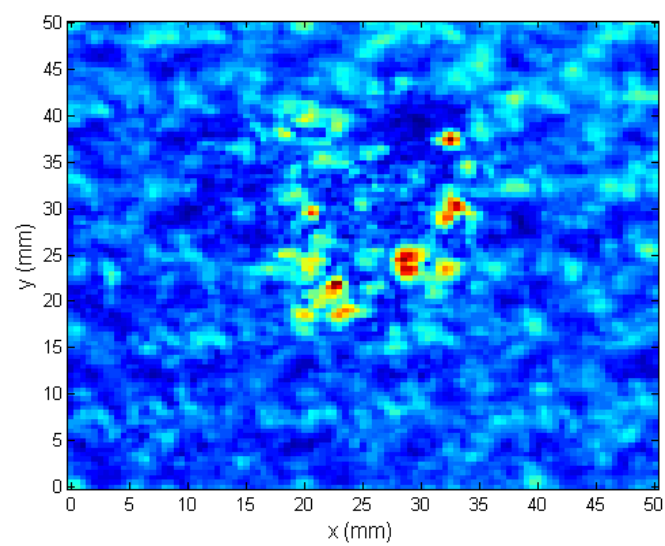

(a)

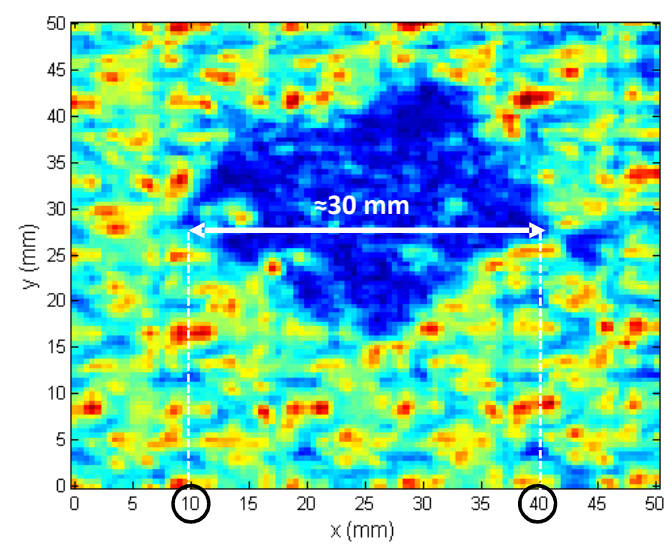

(b)

FIGURE 3. (a) Immersion C-scan of 3D woven composite showing damage and structural noise pattern at a depth of $2 \mathrm{~mm}$ (b) Estimation of the damaged area based on bottom echo attenuation.

\section{DEPTH-DEPENDENT THRESHOLDING BASED ON FBH REFLECTIVITY}

\section{Setting of a depth-dependent threshold}

FBH were machined in the studied specimen at different depths $(20 \%, 40 \%, 60 \%$ and $80 \%$ of the plate thickness) and with different diameters $(1 \mathrm{~mm}, 2 \mathrm{~mm}$ and $4 \mathrm{~mm})$. The reflectivity of these artificial flaws was measured with normal immersion scans using a $5 \mathrm{MHz}$ V309 Panametrics ultrasonic transducer. To estimate the evolution of structural noise with depth, an immersion scan of a $50 \times 50 \mathrm{~mm}^{2}$ was performed in a sound region with the same transducer. A-scan amplitudes were averaged at different depths to yield an estimation of the evolution of the structural noise mean amplitude with depth, as well as the maximum amplitude level reached.

Figure 4 reports the obtained results along with the different echo amplitudes on the different FBH. A strong structural noise level is obtained close to the plate surface. The maximum noise signal amplitude is not obtained at the front surface of the sample but is rather likely a combination of the water/resin interface and the first subsurface carbon fibre bundle. The mean amplitude of this peak was used to normalize all other amplitudes. As it can be observed in Fig.4, all the tested FBH reflectivity amplitudes exceed the mean structural noise. A conservative approach was however taken for thresholding, as the threshold was determined in order to exceed the maximum structural noise at any depth.

The depth-dependent threshold was based on a linear extrapolation of the $1 \mathrm{~mm}$ FBH reflectivity amplitude curve with depth, also plotted in Fig.4. For depths inferior to approximately $0.7 \mathrm{~mm}$, the first structural noise peak discussed above is not thresholded as this echo gives interesting information on the local surface indentation created by the impact. 


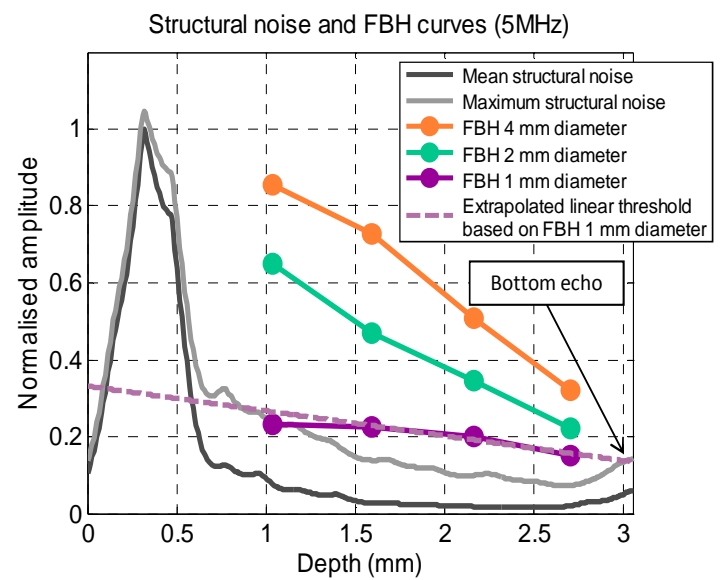

FIGURE 4. Echo amplitudes on different FBH, average and maximum structural noise level with depth.

\section{Application to ultrasonic data obtained on impact damaged areas}

The tested plate specimen was impacted with an Instron drop-weight impact tester, using a 16 mm diameter hemispherical impactor head. Three impacted regions were created with increasing impact energy: $6 \mathrm{~J}, 8.4 \mathrm{~J}$ and $12 \mathrm{~J}$. Scans were performed using the same V309 ultrasonic transducers with a scan step of $0.5 \mathrm{~mm}$ over a $50 \times 50 \mathrm{~mm}^{2}$ area in each impacted zones. Peaks of interest in the collected A-scans were selected based on the previous threshold criterion, after envelope detection. The process is illustrated at Fig.5 for a raw A-scan. For each peak of interest, the $x, y$ scanning positions, the depth $z$, as well as the amplitude $a$ were recorded. The equivalence in FBH reflectivity with depth makes it possible to classify the different selected echoes in terms of an equivalent discontinuity diameter. The amplitudes were broadly classified as $1 \mathrm{~mm}$ diameter equivalent FBH reflectivity (for amplitudes lower than $2 \mathrm{~mm}$ FBH reflectivity), $2 \mathrm{~mm}$ diameter equivalent reflectivity (for amplitudes lower than $4 \mathrm{~mm} F B H$ reflectivity and superior to $2 \mathrm{~mm} \mathrm{FBH}$ reflectivity) and $4 \mathrm{~mm}$ diameter equivalent reflectivity for amplitudes exceeding the $4 \mathrm{~mm}$ FBH reflectivity. Each echo amplitude was also corrected with depth, according to the corresponding classification reflectivity curve.

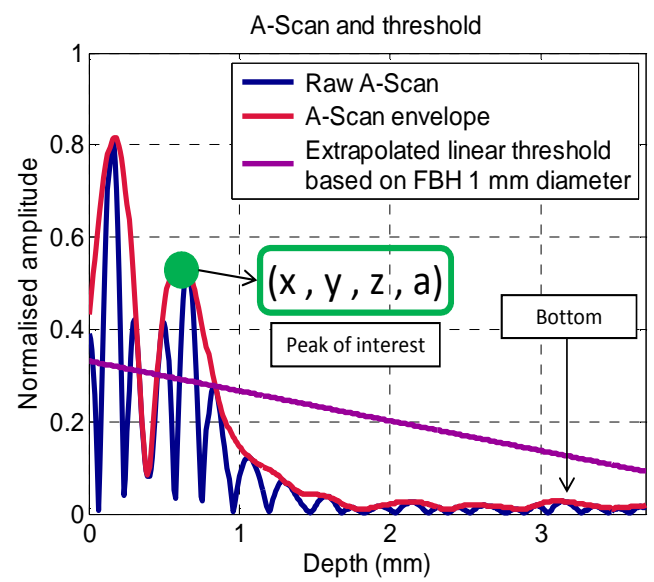

FIGURE 5. Envelope detection and selection of peaks of interest based on the depth-dependent threshold. 


\section{EXPLOITATION OF THE COLLECTED DATA}

\section{Volume representation of damage distribution}

An artificial 3D representation is proposed to render the damage spatial distribution. This representation is built from the coordinates $(x, y, z)$ and amplitude $a$ of each peak in the collected data. A 3D array of zeros is first created. The volume voxel size is adapted to the physical dimensions of the scans $\left(50 \times 50 \times 3 \mathrm{~mm}^{3}\right)$ with an equivalent number of voxels in all the directions. A detected peak is represented as a sphere centered on the peak coordinates and each voxel composing the sphere is attributed an intensity value corresponding to the peak amplitude. The diameter of the sphere is set to the equivalent reflectivity in terms of FBH diameter from the amplitude classification carried out. The process was repeated additively for all the detected peaks. ParaView software was used to render the obtained synthetic volume using a ray casting volume rendering technique. A linear mapping of alpha values (transparency channel) was used to associate zero intensity to full transparency and the maximum voxel intensity to full opacity. Two snapshots of the obtained volume representation are represented at Figure 6.

The great majority of the detected peaks falls in the $1 \mathrm{~mm}$ FBH reflectivity category, so the observed sphere size distribution is very homogeneous. As it may be seen from the top view fig 6.a, the shallow damage distribution exhibits a cross pattern following the weft and warp fibre directions. Inspection of a tilted view reveals the damage distribution with depth. Shallow damage seems to extend over a large radius around the surface indentation created by the impact. The damage distribution at larger depth is approximately confined in a cone extending from the centre of the surface indentation created by the impact.

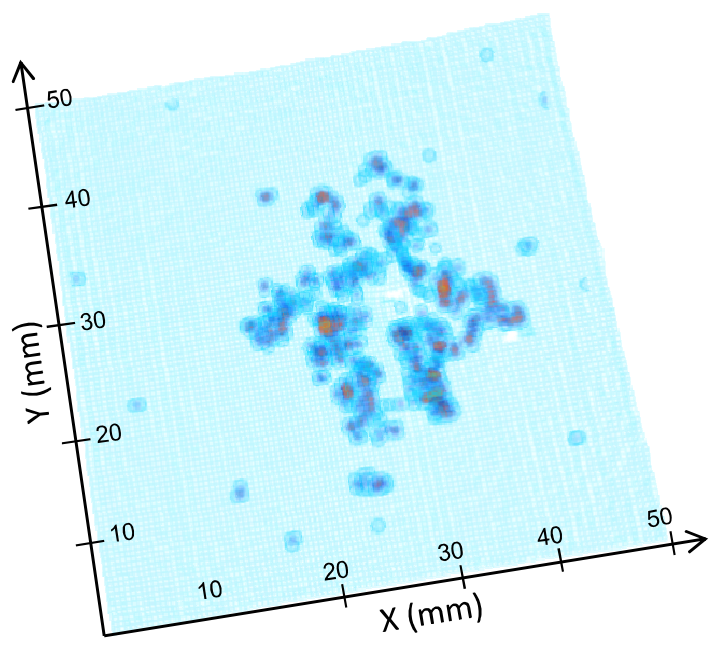

(a)

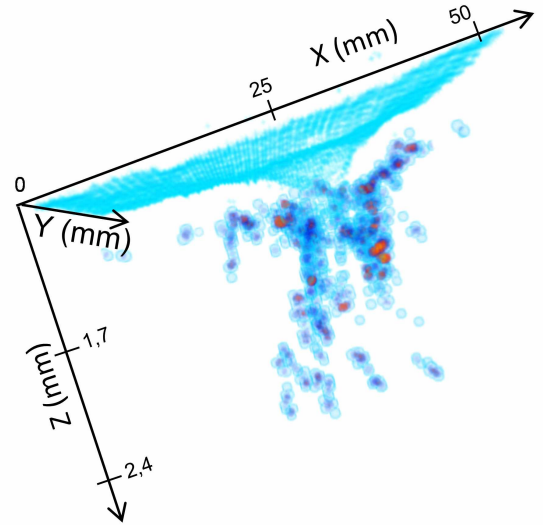

(b)

FIGURE 6. 3D representation of the $12 \mathrm{~J}$ impact damage (a) Top view (b) Tilted view.

\section{Quantitative damage assessment for different impact energies}

The collected data was used to compute different histograms to quantitatively assess the damage created for different impact energies. The first histogram (Fig.6a) shows the detected peak amplitude distribution. A linear decreasing trend may be observed, with the lower amplitudes concentrating the majority of detected peaks. As noticed in the previous section, the great majority of amplitudes falls into the $1 \mathrm{~mm}$ FBH equivalent reflectivity category. A noticeable feature of these distributions is that the increase in impact energy is not accompanied with a significant transfer towards higher energy amplitudes. Comparing the $12 \mathrm{~J}$ and the $6 \mathrm{~J}$ histograms for instance, it can be noticed that damage occurrence (as quantified by the number of ultrasonic echoes exceeding the defined threshold) has more than doubled but the amplitude distribution shape remains stable. This tends to demonstrate that the tested material has a very good impact energy absorption capability. 
Figure 6.b) shows histograms of the radial distribution of damage occurrences from the point of impact for the different impact energies. It can be noticed again that the distribution remains quite stable with increasing impact energy. The bulk of damage is confined in an area of radius approximately $15 \mathrm{~mm}$ with a peak in the distribution observed around a radius of $7.5 \mathrm{~mm}$. This again quantitatively demonstrates the good resistance of this type of material in terms of damage extent progression with increasing impact energies.

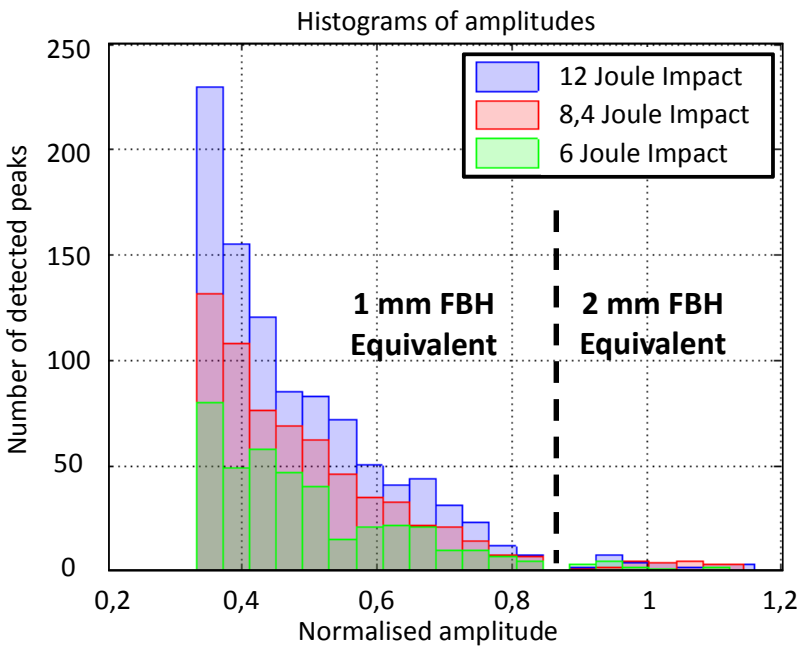

(a)

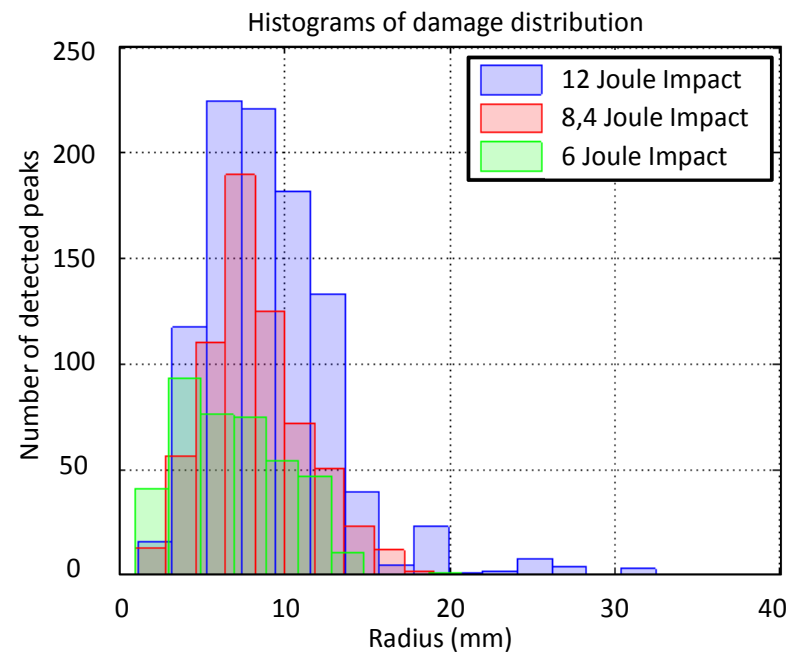

(b)

FIGURE 6. Histograms computed from data collected for different impact energies (a) histograms of detected peak amplitudes (b) histograms of radial position of detected peaks from the point of impact.

\section{CONCLUSION}

A quantitative assessment of 3D woven composites impact-induced damage based on ultrasonic testing was proposed. The approach uses FBH machined into the specimen to provide a depth-dependent reference reflectivity. This makes it possible to retain only peaks of interests in the collected A-scans in damaged areas and to filter out echoes from the complex 3D reinforcement pattern of the material. The collected data was used to build an artificial volume representation of damage created by different impact energy levels. The proposed volume representation is arguably more adapted to the damage morphology of this type of materials than the standard C-scan representations. Indeed microscopic observations show that damage may occur at very different scales and does not confine in a plane perpendicular to the axis of insonification as in the case of delaminations in unidirectional laminates. The approach furthermore makes it possible to compute different statistics on the detected amplitudes to quantitatively assess the impact resistance of the tested material. It was for instance observed that the distribution shape of peak amplitudes remained remarkably stable when doubling the impact energy, demonstrating the capability of the tested material to dissipate impact energy by the creation of multiple small-sized defects. Despite a set of obvious limitations (low sensitivity to small and very disoriented defects, masking effects of low depth damage, rough classification in terms of FBH diameters,...), the method provides a relatively fast and cost-effective alternative for the quantitative assessment of impact-induced damage in 3D woven composite materials. Future work will focus on a comparison with other available techniques (microscopic observations, X-ray Computed Tomography,...)..

\section{REFERENCES}

1. Mouritz, A. P., et al. "Review of applications for advanced three-dimensional fibre textile composites." Composites Part A: applied science and manufacturing 30, 1445-1461, (1999). 
2. Chen, F., and J. M. Hodgkinson, "Impact behaviour of composites with different fibre architecture." Proceedings of the Institution of Mechanical Engineers, Part G: Journal of Aerospace Engineering 223,10091017, (2009).

3. Ansar, M., Xinwei, W., and Chouwei, Z., "Modeling strategies of 3D woven composites: a review.", Composite structures 93, 1947-1963, (2011).

4. Lomov, S. V., et al., "Textile composites: modeling strategies.", Composites Part A: applied science and manufacturing 32, 1379-1394, (2001).

5. Hufenbach, W., et al., "Theoretical and experimental investigation of anisotropic damage in textile-reinforced composite structures." Mechanics of Composite Materials 40, 519-532, (2004).

6. Lomov, S. V., et al. "Experimental methodology of study of damage initiation and development in textile composites in uniaxial tensile test." Composites Science and Technology 68, 2340-2349, (2008).

7. Böhm, R., and Hufenbach, W. "Experimentally based strategy for damage analysis of textile-reinforced composites under static loading." Composites Science and Technology 70, 1330-1337, (2010).

8. Naik, N. K., Y. Sekher C., and Meduri S., "Damage in woven-fabric composites subjected to low-velocity impact." Composites Science and Technology 60, 731-744, (2000).

9. Chin, C.H., Lai, M.H., and Wu, C. M., "Compression failure mechanisms of 3-D angle interlock woven composites subjected to low-energy impact." Polymers \& polymer composites 12, 309-320, (2004).

10. Elias A. et al., Study of low velocity impact defects in organic interlock woven composite, ECCM16 Seville, Spain, 22-26 June 2014.

11. Zumpano Z. et al., "Impact damage to 3D woven CFRP composites plates", Proceedings ICCM-17, Edinburgh, 27-31 July 2009. 




\section{ONERA}

BP 72 - 29 avenue de la Division Leclerc - 92322 CHATILLON CEDEX - Tél. : +33 146734040 - Fax : +33 146734141

w w w. onera.f r 